This is the peer reviewed version of the following article: Lafarga, T., Gallagher, E., Bademunt, A., Viñas, I., Bobo, G., Villaró, S., \& Aguiló-Aguayo, I. (2019). Bioaccessibility, physicochemical, sensorial, and nutritional characteristics of bread containing broccoli co-products. Journal Of Food Processing And Preservation, 43(2), e13861. doi:10.1111/jfpp.13861. This article may be used for non-commercial purposes in accordance with Wiley Terms and Conditions for Use of Self-Archived Versions http://www.wileyauthors.com/self-archiving.

Document downloaded from: 


\section{Bioaccessibility and antioxidant activity of phenolic compounds in}

\section{2 cooked pulses}

3 Tomás Lafarga a ${ }^{\text {a }}$, Silvia Villaró ${ }^{\text {a }}$, Gloria Bobo a ${ }^{\text {a }}$ Joan Simó ${ }^{\text {b }}$, and Ingrid Aguiló-Aguayo ${ }^{\text {a* }}$

4 a IRTA, XaRTA-Postharvest, Parc Científic i Tecnològic Agroalimentari de Lleida, Parc de 5 Gardeny, Edifici Fruitcentre, 25003, Lleida, Catalonia, Spain.

6 b ${ }^{\text {b }}$ Fundació Miquel Agustí, Campus del Baix Llobregat, Esteve terrades 8, 08860 Castelldefels, 7 Spain.

8

9

10 * Corresponding author:

11 Dr. Aguiló-Aguayo; Phone: +34 973003431; email: Ingrid.Aguilo@irta.cat

12

\section{Abbreviations:}

14 TPC: total phenolic content; DPPH: 2,2-diphenyl-1-picrylhydrazyl; TPTZ: tris(215 carboxyethyl)phosphine hydrochloride; FRAP: ferric reducing antioxidant power; S.D.: 16 standard deviation; ANOVA: analysis of variance. 


\section{Abstract}

18 The aim of this study was to evaluate the bioaccessibility of polyphenols and

19 antioxidant activity in cooked pulses and to study the effect of cooking on their total

20 phenolic content (TPC) and antioxidant capacity. Cooked faba beans showed the

21 highest TPC, followed by soybeans and lentils or peas. TPC ranged from $10.4 \pm 0.2$ to

$2252.9 \pm 0.3 \mathrm{mg} / 100 \mathrm{~g}$ and was positively correlated with antioxidant activity. Cooking

23 resulted in increased TPC and antioxidant activity of the methanolic extracts, caused by

24 cell disruption and improved extraction of polyphenols. Although polyphenols were lost

25 in the cooking water, boiled legumes had more polyphenols than those resulting

26 cooking broths. In vitro gastrointestinal digestion resulted in increased TPC and

27 antioxidant capacity of the extracts. Soybeans showed the highest amount of

28 bioaccessible polyphenols. The release of phenolics from cooked legumes was mainly

29 achieved during the intestinal phase. Literature data may underestimate the TPC and

30 antioxidant capacity of pulses.

31 Keywords: bioaccessibility, polyphenols, pulses, in vitro digestion, antioxidant activity,

32 boiling 


\section{Introduction}

34 Pulses, which include lentils, beans, chickpeas, and soybeans provide an important source of proteins, fibres, minerals, vitamins, and bioactive compounds such as polyphenols and other phytochemicals (Giusti et al,. 2017). A large amount of evidence supports the cardioprotective, anticarcinogenic, anticholesterolemic, and antioxidant properties of pulses (Singh et al,. 2017, López-Martínez et al,. 2017). To highlight their present and future importance as nutritious protein-rich foods, the Food and Agriculture Organization of the United Nations declared 2016 the International Year of Pulses

\section{1 (Vollmann 2016).}

Pulses are thermally processed in order to obtain desirable textures and flavours and are not commonly eaten raw. Therefore, the effect of pressure, temperature, or $\mathrm{pH}$ variations that occur during thermal processing of pulses and other foods is of key importance. For example, glucosinolates found in cruciferous vegetables and seeds have been proved to be heavily lost during thermal processing (Lafarga et al,. 2018a). In addition, thermal processing of pulses including toasting, steaming, boiling, and autoclaving usually degrade and reduce the content of phytic acid and other phenolic compounds (López-Martínez et al,. 2017). Health benefits of foods depend not only on their resistance to thermal processing or intake levels but also on their bioavailability.

51 Bioavailability can be defined as the fraction of ingested component available for utilization in normal physiological functions (Cilla et al,. 2018). Bioavailability includes another additional term, bioaccessibility, which is defined as the release of compounds

54 from their natural food matrix to be available for intestinal absorption and is one of the 55 main limiting factors for bioavailability (Stahl et al,. 2002). Knowledge on resistance to cooking conditions and on bioaccessibility as the first step of bioavailability is of great interest to ascertain the nutritional quality of a food 
58 product. Therefore, the aim of this study was to evaluate the bioaccessibility of 59 polyphenols and antioxidant activity in a number of pulses namely lentils, cowpeas, 60 faba beans, chickpeas, soybeans, runner beans, common beans, and peas. A secondary 61 aim of this paper was to study the effect of cooking on the total phenolic content (TPC) 62 and antioxidant capacity of selected pulses. Assessment of the bioaccessibility and 63 nutritional quality in different varieties of cooked pulses may assist health programmes 64 and add economic and nutritional value to these foods. 


\section{Materials and methods}

66

67

68

69

70

\subsection{Chemicals and reagents}

Methanol and ferric chloride were purchased from Panreac (Barcelona, Spain). Gallic acid, ascorbic acid, hydrochloric acid, 2,4,6-tris(2-pyridyl)-s-triazine (TPTZ), 2,2diphenyl-1-picrylhydrazyl (DPPH), tris(2-carboxyethyl)phosphine hydrochloride (TCEP), potassium phosphate monobasic, potassium phosphate dibasic, calcium chloride, 1,2- benzenedithiol, $\alpha$-amylase (EC 3.2.1.1), pepsin (EC 3.4.23.1), pancreatin, fresh bile, sodium hydroxide, ammonium sulphate, and sodium carbonate were purchased from Sigma-Aldrich (Steinheim, Germany). Folin-Ciocalteu's reagent was purchased from VWR (Llinars del Vallès, Spain). All reagents used were of analytical grade.

\subsection{Thermal processing}

Dry legumes, shown in Figure 1, were sown in July 2017 in an open field in Northeast Spain $\left(41^{\circ} 30^{\prime} 08.2^{\prime \prime} \mathrm{N}, 2^{\circ} 01^{\prime} 02.2^{\prime \prime} \mathrm{E}\right)$ and were cultivated using the traditional methods in the area including drip irrigation. Legumes were divided into two lots. The first lot was milled to a thin powder using a MINIMOKA GR-020 grinder (Taurus Group, Barcelona, Spain), passed through a sieve of $1 \mathrm{~mm}$, and stored at $-20{ }^{\circ} \mathrm{C}$ until further use. The second lot was soaked in tap water at a sample:water ratio of 1:10 (w/v) at room temperature for $24 \mathrm{~h}$ (as it is generally done in Spanish homes). After this period, the soaking water was discarded and the soaked beans were boiled at a sample:water ratio of 1:10 (w/v) as described by de Oliveira et al,. (2018). Boiling times, shown in Figure 1, were optimised by preliminary experiments carried out for each variety in which samples were considered cooked according to the judgement of a group of semi-trained panellists. For all processing treatments, the minimum time 
needed to reach tenderness for an adequate palatability and taste (according the Spanish

90 eating habits) was used. Immediately after processing, samples were chilled to

91 approximately $4{ }^{\circ} \mathrm{C}$ using an ABT 101L blast chiller (Infrico, Barcelona, Spain), milled

92 using a MINIMOKA GR-020 grinder (Taurus Group, Barcelona, Spain), and stored at -

$9320^{\circ} \mathrm{C}$ until further use. Thermal processing was carried out in triplicate for each sample.

\section{$94 \quad 2.3$ Determination of total phenolic content}

95 The TPC was determined by the Folin Ciocalteu method. Briefly, for the extraction of

96 polyphenols from raw, soaked, and cooked legumes, the samples were homogenized

97 with methanol $70 \%(\mathrm{v} / \mathrm{v})$ at a sample:methanol ratio of $1: 4(\mathrm{w} / \mathrm{v})$ at $4{ }^{\circ} \mathrm{C}$.

98 Homogenization was performed using a T-25 ULTRA-TURRAX ${ }^{\circledR}$ homogenizer (IKA,

99 Staufem, Germany) operating at $12,000 \mathrm{rpm}$ for $30 \mathrm{~s}$. Homogenized samples were

100 immediately place in a stirrer at room temperature for $2 \mathrm{~h}$ and centrifuged using a

101 Sigma-3-18 KS centrifuge (Sigma Laborzentrifugen GmbH, Osterode am Harz,

102 Germany) at $10,000 \times g$ for $20 \mathrm{~min}$.

103 To determine the TPC of boiling water and gastric or intestinal digestive extracts,

104 proteins were first precipitated by saturation using ammonium sulphate as described by

105 García-Vaquero et al,. (2017). The assay was performed by adding $4.3 \mathrm{~mL}$ of MilliQ

106 water and $0.5 \mathrm{~mL}$ of Folin-Ciocalteu's reagent to $0.7 \mathrm{~mL}$ of methanolic or digestive

107 extract. After incubation for $5 \mathrm{~min}$ at room temperature in the dark, $2 \mathrm{~mL}$ of saturated

108 sodium carbonate solution was added. The mixture was shaken and further incubated

109 for $1 \mathrm{~h}$ at room temperature and in the dark. Absorbance was read at $760 \mathrm{~nm}$ using a

110 GENESYS $^{\mathrm{TM}}$ 10S UV-Vis spectrophotometer (Thermo Fisher Scientific, MA, USA).

111 TPC was determined in triplicate and results were expressed as mg of gallic acid

112 equivalents per $100 \mathrm{~g}$ of dry weight (DW). Standard curves were prepared daily. 


\subsection{Antioxidant activity}

114 Antioxidant activity was assessed using two different methods: the ferric reducing 115 antioxidant power (FRAP) and the DPPH scavenging activity assays. Both

116 determinations were performed on the same extract used for the determination of TPC 117 and following the methodology described by Lafarga et al,. (2018b) with some 118 modifications.

\subsubsection{FRAP assay}

120 The FRAP reagent was freshly prepared by mixing $0.3 \mathrm{M}$ acetate buffer (pH 3.6), 10 $\mathrm{mM}$ TPTZ in $40 \mathrm{mM}$ hydrochloric acid, and $20 \mathrm{mM}$ ferrous chloride in the proportion 10:1:1 (v/v/v). Determinations were carried out by mixing $1.4 \mathrm{~mL}$ of the FRAP reagent and $0.1 \mathrm{~mL}$ of the methanolic extract obtained following the methodology described

124 above. After 20 min of incubation in the dark at $37{ }^{\circ} \mathrm{C}$ and constant shaking, the 125 absorbance was read at $593 \mathrm{~nm}$ using a GENESYS ${ }^{\mathrm{TM}}$ 10S UV-Vis spectrophotometer

126 (Thermo Fisher Scientific, MA, USA). Antioxidant activity assessed using the FRAP assay was determined in triplicate and expressed as mg of ascorbic acid equivalents per $100 \mathrm{~g}$ of DW. Standard curves were prepared daily.

\subsubsection{DPPH assay}

130 The assay was performed by adding $1.4 \mathrm{~mL}$ of $0.1 \mathrm{mM} \mathrm{DPPH}$. solution to $0.1 \mathrm{~mL}$ of the

131 methanolic extract obtained as described above. After $60 \mathrm{~min}$ of incubation at room

132 temperature and in the dark, the absorbance was read at $515 \mathrm{~nm}$ using a using a

133 GENESYS ${ }^{\mathrm{TM}}$ 10S UV-Vis spectrophotometer (Thermo Fisher Scientific, MA, USA).

134 Antioxidant activity assessed using the DPPH assay was determined in triplicate and 135 expressed as mg of ascorbic acid equivalents per $100 \mathrm{~g}$ of DW. Standard curves were 136 prepared daily. 


\section{$137 \quad 2.5$ Simulated gastrointestinal digestion}

138 A simulated gastrointestinal digestion was performed following the standardised static

139 in vitro method previously described by Minekus et al,. (2014). This method is an

140 international consensus which consists of three sequential states: (i) oral ( $\mathrm{pH} 7.0, \alpha-$

141 amylase), (ii) gastric ( $\mathrm{pH} 3.0$, pepsin), and (iii) intestinal ( $\mathrm{pH} 7.0$, pancreatin and fresh

142 bile). The pancreatin used contained enzymatic components including trypsin, amylase

143 and lipase, ribonuclease, and protease, produced by the exocrine cells of the porcine

144 pancreas, which allow hydrolysing proteins, starch, and fats. The simulated digestion

145 was performed in triplicate for each sample and a blank was prepared using only

146 distilled water instead of sample and following the same procedure. Determinations of

147 TPC and antioxidant activity were carried out in triplicate after both gastric and 148 intestinal phase.

\section{$149 \quad 2.6$ Statistical analysis}

150 Results are expressed as mean \pm standard deviation (S.D.). Difference between samples

151 were analysed using analysis of variance (ANOVA) with JMP 13 (SAS Institute Inc.,

152 Cary, USA). Where significant differences were present, a Tukey pairwise comparison

153 of the means was conducted to identify where the sample differences occurred. The

154 criterion for statistical significance was $p<0.05$. 


\section{Results and discussion}

\section{$156 \quad 3.1$ Total phenolic content and antioxidant capacity of dry legume seeds}

157 Dry soybeans showed the highest TPC, followed by faba beans, and lentils (Table 1; $158 p<0.05)$. TPC ranged from $14.70 \pm 0.13$ to $37.14 \pm 0.29 \mathrm{mg} / 100 \mathrm{~g} \mathrm{DW}$ and was 159 positively correlated with FRAP $\left(r^{2}=0.680 ; p<0.05\right)$ and DPPH $\left(r^{2}=0.620 ; p<0.05\right)$

160 values. Results were comparable to those reported previously for dry pulses such as

161 chickpeas, with TPC values ranging between 2.78 to $12.7 \mathrm{mg} / 100 \mathrm{~g}$ and field peas

162 (Pisum sativum) with TPC values ranging between 9.6 to $25.4 \mathrm{mg} / 100 \mathrm{~g}$ (Magalhaes et $163 a l$,. 2017). Results were also comparable to those reported by Parikh and Patel (2018), 164 who calculated the TPC of field beans and white cowpeas as 41.4 and $39.9 \mathrm{mg} / 100 \mathrm{~g}$. 165 Antioxidant activity of selected pulses assessed using the FRAP and DPPH methods is 166 shown in Table 1. In the current study, dry faba beans showed the highest antioxidant 167 capacity when assessed using both the FRAP and DPPH assays $(p<0.05)$. Similar 168 antioxidant capacity values were reported for dry pulses previously (Parikh and Patel 169 2018). The highest antioxidant capacity of faba beans could be attributed to a higher 170 content of coloured polyphenols such as tannins, anthocyanins, or proanthocyanins. $\mathrm{Xu}$ 171 et al,. (2007) suggested that antioxidant capacity of pulses is mainly caused by the 172 coloured pigments found in their seed coats and positive correlations have been 173 associated with dark colours and antioxidant capacities of legume seeds previously 174 (Dueñas et al,. 2006). In addition, Gan et al,. (2016) recently reported a higher TPC and 175 antioxidant capacity of coloured sword bean varieties when compared to the white ones, 176 especially in their bean coats and Siah et al,. (2014) reported total proanthocyanin 177 contents ranging between 0.11 to $0.32 \mathrm{mg} / \mathrm{g}$ for different faba bean varieties. 

selected pulses

180 The cooking method used in the current study mimics common domestic cooking 181 methods, which generally include a rinsing and soaking step before boiling. Therefore, 182 TPC determinations made herein are likely to closely represent a usual intake of these 183 pulses when consumed at home. The effect of soaking and boiling on the TPC of 184 selected legumes is shown in Table 1. Soaking in tap water for $24 \mathrm{~h}$ resulted in a significant decrease of the TPC $(p<0.05)$. Soaking resulted in reduced phenolic content previously (Haileslassie et al,. 2016). Percentage of TPC loss after soaking ranged between 3.4 (soybeans) and $26.6 \%$ (common beans). When expressed on a wet weight

188 basis, boiling resulted in decreased TPC $(p<0.05)$. However, when calculated on a DW 189 basis, boiling resulted in increased TPC $(p<0.05)$, probably due to a higher extraction 190 yield caused by cell disruption during cooking. Similar results were observed previously

191 after thermal processing of legumes (Siah et al,. 2014). Results showed in next sections 192 also support this hypothesis. Cooking resulted in decreased TPC when calculated on a 193 wet weight basis previously (Garretson et al,. 2018). Decreased TPC values after 194 cooking were attributed to dissolution of polyphenols in water, degradation of phenolics 195 during processing, or chemical transformations previously (Bubelová et al,. 2018). In 196 the current study, the amount of polyphenols lost in the boiling water are shown in

197 Table 2. Similar results were reported by Siah et al,. (2014), who observed that a 198 significant amount of polyphenols was leaked to the cooking medium, but that boiled 199 beans had a higher TPC than those of resulting cooking broths. These results support the 200 hypothesis that the observe increase in the TPC was caused by an inefficient extraction 201 from raw legumes. 
202 Boiling led to an overall increased antioxidant activity of the extracts when assessed

203 using both the FRAP and DPPH methods ( $p<0.05$ ), caused by a higher TPC. Indeed, a 204 positive correlation was observed between TPC and FRAP $\left(r^{2}=0.816 ; p<0.001\right)$ or

205 DPPH values $\left(r^{2}=0.639 ; p<0.05\right)$ for cooked samples. Both the antioxidant capacity 206 and the TPC of the boiling water were calculated after protein precipitation. Protein 207 precipitation led to a significantly lower TPC and antioxidant activity $(p<0.05)$. These 208 could be caused by protein interactions with the Folin-Ciocalteu reagent and to the 209 generation of antioxidant peptides during cooking.

\section{$210 \quad 3.3$ Bioaccessibility of total phenols and antioxidant activity}

211 Cooked soybeans followed by faba beans and lentils showed the highest amount of 212 bioaccessible polyphenols $(p<0.05$; Table 3$)$. The TPC was higher after the gastric and

213 intestinal phases of digestion of all samples when compared to the initial stage $(p<0.05)$.

214 Similar results were obtained previously for other foods such as cereals (Pérez-Jiménez 215 and Saura-Calixto 2005). Enzymatic hydrolysis of mung bean and adzuki bean also 216 resulted in an increased release of polyphenols previously (Sangsukiam and Duangmal 217 2017). However, results contrast with those reported by Zhang et al,. (2017), who 218 calculated the TPC of cooked green lentils after a water:methanol extraction as 618 $219 \mathrm{mg} / 100 \mathrm{~g}$ and the bioaccessibility after a simulated gastrointestinal digestion as $51 \%$.

220 The lower extraction time used by Zhang et al,. (2017) could partially explain their 221 findings, as the methanolic extract was obtained in that study after extraction for over $22215 \mathrm{~h}$ and the enzymatic digestive extracts were obtained after an approximately $3 \mathrm{~h}$ 223 digestion. Phenolic compounds exist in free, soluble conjugated, and insoluble bound 224 forms. Although free and some conjugated phenolic compounds are thought to be 225 available for absorption in the human small and large intestines, those bound covalently to indigestive polysaccharides may be absorbed after being released from cell structures 
227 by digestive enzymes or microorganisms in the intestinal lumen (Wang et al,. 2014).

228 Chemical structure and matrix interactions can affect the bioaccessibility. Indeed, Chen 229 et al,. (2015) observed an increase in TPC after the intestinal phase when compared to 230 the gastric phase of digestion, suggesting that the release of phenolics from cooked 231 lentils is mainly achieved during the intestinal phase. The same trend was observed by 232 Zhang et al,. (2017), who observed higher total phenolic, flavonoid, and tannin contents 233 after the intestinal phase when compared to gastric digestion. Finally, Pérez-Jiménez 234 and Saura-Calixto (2005) reported that TPC and antioxidant activity of the digestive 235 enzymatic extracts (of cereals) were significantly higher when compared to that of the 236 water-organic extracts and that literature data may underestimate the actual TPC and 237 antioxidant capacity of cereals. Results obtained herein support the hypothesis that the 238 release of phenolics from cooked legumes is mainly achieved during the intestinal 239 phase.

240 Moreover, the antioxidant capacity of the digestive enzymatic extracts obtained after 241 gastric and gastrointestinal digestion, was assessed using the FRAP and DPPH assays. 242 Results, listed in Table 4 and Table 5 respectively, correlate well to those obtained for 243 TPC, as the antioxidant capacity was higher after gastrointestinal digestion $(p<0.05)$. 244 Indeed, a positive correlation was observed between the TPC and the FRAP $\left(r^{2}=0.913\right.$; $245 p<0.05)$ and DPPH $\left(r^{2}=0.798 ; p<0.05\right)$ values after in vitro digestion of cooked 246 samples. Boiling facilitated the release of polyphenols from the different legume 247 varieties. This is clear from the data, as the TPC after the intestinal phase of digestion 248 was higher for cooked samples when compared to those digested raw $(p<0.05)$. 249 Previous studies also reported an increased bioaccessible polyphenolic content of 250 roasted pearl millet, green gram, and finger millet when compared to those in their 251 native state (Hithamani and Srinivasan, 2017). Cilla et al,. (2018) recently reviewed the 
252 effect of processing on the bioaccessibility of bioactive compounds and concluded that 253 thermal processing can exert a positive or a negative effect, depending on the food 254 matrix and on the processing conditions. Antioxidant capacity of digestive enzymatic 255 extracts was also higher for cooked samples $(p<0.05)$. Although the current study 256 included a protein precipitation step, in order to avoid the interference of proteins with 257 the TPC determination method, short peptides could still be soluble at high salt 258 concentrations. Thus, the observed increase in antioxidant capacity could be also 259 attributed to the generation of antioxidant peptides, as pulses are protein-rich foods 260 (Nosworthy et al,. 2017) and excellent sources of bioactive peptides (Sangsukiam and 261 Duangmal, 2017). 


\section{Conclusions}

263 Legumes are rich sources of not only proteins but also polyphenols. Boiling increased 264 both the content of polyphenols and the in vitro antioxidant capacity of the methanolic 265 extracts obtained from selected pulses. This was caused by an inefficient extraction 266 from the raw samples, which was improved after the cell disruption caused during 267 cooking. Although the cooking water contained significant quantities of polyphenols, 268 boiled legumes had more polyphenols than those resulting cooking broths. The TPC and 269 antioxidant capacity of the digestive enzymatic extracts obtained after in vitro digestion

270 was higher when compared to that observed for water:methanol extracts. Protein 271 precipitation prior to assessment of TPC resulted in significantly lower values, as 272 proteins can interfere in the determination. Results suggest that literature data may 273 underestimate the actual TPC and antioxidant capacity of pulses and support the 274 hypothesis that the release of phenolics from cooked legumes is mainly achieved during 275 the intestinal phase. 
277 This work was supported by the CERCA Programme of Generalitat de Catalunya. T.

278 Lafarga is in receipt of Juan de la Cierva contract awarded by the Spanish Ministry of 279 Economy, Industry, and Competitiveness (FJCI-2016-29541). I. Aguiló-Aguayo thanks 280 the National Programme for the Promotion of Talent and its Employability of the 281 Spanish Ministry of Economy, Industry and Competitiveness and to the European 282 Social Fund for the Postdoctoral Senior Grant Ramon y Cajal (RYC-2016-19949). 
283 Conflict of interests

284 The authors declare no conflict of interests 
286

287

288

289

290

291

292

293

294

295

296

297

298

299

300

301

302

303

304

305

306

307

308

309

310

311

312

313

314

315

316

317

318

319

320

321

322

323

324

325

326

Bubelová, Z., Sumczynski, D. \& Salek, R. N. (2018). Effect of cooking and germination on antioxidant activity, total polyphenols and flavonoids, fiber content, and digestibility of lentils (Lens culinaris L.). Journal of Food Processing and Preservation, 42, e13388.

Chen, P. X., Dupuis, J. H., Marcone, M. F., Pauls, P. K., Liu, R., Liu, Q., Tang, Y., Zhang, B. \& Tsao, R. (2015). Physicochemical properties and in vitro digestibility of cooked regular and nondarkening cranberry beans (Phaseolus vulgaris L.) and their effects on bioaccessibility, phenolic composition, and antioxidant activity. Journal of Agricultural and Food Chemistry, 63, 1044810458.

Cilla, A., Bosch, L., Barberá, R. \& Alegría, A. (2018). Effect of processing on the bioaccessibility of bioactive compounds - A review focusing on carotenoids, minerals, ascorbic acid, tocopherols and polyphenols. Journal of Food Composition and Analysis, 68, 3-15.

de Oliveira, A. P., Mateó, B. d. S. O., Fioroto, A. M., de Oliveira, P. V. \& Naozuka, J. (2018). Effect of cooking on the bioaccessibility of essential elements in different varieties of beans (Phaseolus vulgaris L.). Journal of Food Composition and Analysis, 67, 135-140.

Dueñas, M., Hernandez, T. \& Estrella, I. (2006). Assessment of in vitro antioxidant capacity of the seed coat and the cotyledon of legumes in relation to their phenolic contents. Food Chemistry, 98, 95-103.

Gan, R.J., Lui, W.Y. \& Corke, H. (2016). Sword bean (Canavalia gladiata) as a source of antioxidant phenolics. International Journal of Food Science \& Technology, 51, 156-162.

García-Vaquero, M., López-Alonso, M. \& Hayes, M. (2017). Assessment of the functional properties of protein extracted from the brown seaweed Himanthalia elongata (Linnaeus) S. F. Gray. Food Research International, 99, 971-978.

Garretson, L., Tyl, C. \& Marti, A. (2018). Effect of Processing on Antioxidant Activity, Total Phenols, and Total Flavonoids of Pigmented Heirloom Beans. Journal of Food Quality, 2018, 786745.

Giusti, F., Caprioli, G., Ricciutelli, M., Vittori, S. \& Sagratini, G. (2017). Determination of fourteen polyphenols in pulses by high performance liquid chromatographydiode array detection (HPLC-DAD) and correlation study with antioxidant activity and colour. Food Chemistry, 221, 689-697.

Gujral, H. S., Angurala, M., Sharma, P. \& Singh, J. (2011). Phenolic content and antioxidant activity of germinated and cooked pulses. International Journal of Food Properties, 14, 1366-1374.

Haileslassie, H.A., Henry, C.J. \& Tyler, R.T. (2016). Impact of household food processing strategies on antinutrient (phytate, tannin and polyphenol) contents of chickpeas (Cicer arietinum L.) and beans (Phaseolus vulgaris L.): A review. International Journal of Food Science \& Technology, 51, 1947-1957. 
Hithamani, G. \& Srinivasan, K. (2017) Bioaccessibility of polyphenols from selected cereal grains and legumes as influenced by food acidulants. Journal of the Science of Food and Agriculture, 97, 621-628.

Lafarga, T., Bobo, G., Viñas, I., Collazo, C. \& Aguiló-Aguayo, I. (2018a). Effects of thermal and non-thermal processing of cruciferous vegetables on glucosinolates and its derived forms. Journal of Food Science and Technology, 55, 1973-1981.

Lafarga, T., Viñas, I., Bobo, G., Simó, J. \& Aguiló-Aguayo, I. (2018b). Effect of steaming and sous vide processing on the total phenolic content, vitamin $\mathrm{C}$ and antioxidant potential of the genus Brassica. Innovative Food Science \& Emerging Technologies, 47, 412-420.

López-Martínez, L. X., Leyva-López, N., Gutiérrez-Grijalva, E. P. \& Heredia, J. B. (2017). Effect of cooking and germination on bioactive compounds in pulses and their health benefits. Journal of Functional Foods, 38, 624-634.

Magalhaes, S. C., Taveira, M., Cabrita, A. R., Fonseca, A. J., Valentão, P. \& Andrade, P. B. (2017). European marketable grain legume seeds: further insight into phenolic compounds profiles. Food Chemistry, 215, 177-184.

Minekus, M., Alminger, M., Alvito, P., Ballance, S., Bohn, T., Bourlieu, C., Carriere, F., Boutrou, R., Corredig, M. \& Dupont, D. (2014). A standardised static in vitro digestion method suitable for food-an international consensus. Food \& Function, 5, 1113-1124.

Nosworthy, M. G., Neufeld, J., Frohlich, P., Young, G., Malcolmson, L. \& House, J. D. (2017). Determination of the protein quality of cooked Canadian pulses. Food Science \& Nutrition, 5, 896-903.

Parikh, B. \& Patel, V. (2018). Total phenolic content and total antioxidant capacity of common Indian pulses and split pulses. Journal of Food Science and Technology, 55, 1499-1507.

Pérez-Jiménez, J. \& Saura-Calixto, F. (2005). Literature Data May Underestimate the Actual Antioxidant Capacity of Cereals. Journal of Agricultural and Food Chemistry, 53, 5036-5040.

Sangsukiam, T. \& Dungmal, K. (2017). A comparative study of physico-chemical properties and antioxidant activity of freeze-dried mung bean (Vigna radiata) and adzuki bean (Vigma angularis) sprout hydrolysate powders. International Journal of Food Science \& Technology, 52, 1971-1982.

Siah, S., Wood, J. A., Agboola, S., Konczak, I. \& Blanchard, C. L. (2014). Effects of soaking, boiling and autoclaving on the phenolic contents and antioxidant activities of faba beans (Vicia faba L.) differing in seed coat colours. Food Chemistry, 142, 461-468.

Singh, B., Singh, J. P., Shevkani, K., Singh, N. \& Kaur, A. (2017). Bioactive constituents in pulses and their health benefits. Journal of Food Science and Technology, 54, 858-870.

Stahl, W., van den Berg, H., Arthur, J., Bast, A., Dainty, J., Faulks, R. M., Gärtner, C., Haenen, G., Hollman, P. \& Holst, B. (2002). Bioavailability and metabolism. Molecular Apects of Medicine, 23, 39-100. 
Vollmann, J. (2016). Soybean versus other food grain legumes: a critical appraisal of the United Nations International Year of Pulses 2016. Die Bodenkultur: Journal of Land Management, Food and Environment, 67, 17-24.

Wang, T., He, F. \& Chen, G. (2014). Improving bioaccessibility and bioavailability of phenolic compounds in cereal grains through processing technologies: A concise review. Journal of Functional Foods, 7, 101-111.

Xu, B., Yuan, S. \& Chang, S. (2007). Comparative analyses of phenolic composition, antioxidant capacity, and color of cool season legumes and other selected food legumes. Journal of Food Science, 72, S167-S177.

Zhang, B., Deng, Z., Tang, Y., Chen, P. X., Liu, R., Dan Ramdath, D., Liu, Q., Hernandez, M. \& Tsao, R. (2017). Bioaccessibility, in vitro antioxidant and antiinflammatory activities of phenolics in cooked green lentil (Lens culinaris). Journal of Functional Foods, 32, 248-255. 
$383 \quad$ Legends to Figure

$384 \quad$ Figure 1. Studied legumes 
Table 1. Total phenolic content and antioxidant activity of raw, soaked, and cooked legumes

\begin{tabular}{|c|c|c|c|c|c|c|c|c|c|}
\hline \multirow[b]{2}{*}{ Sample } & \multicolumn{3}{|c|}{ TPC (mg/ 100 g DW) } & \multicolumn{3}{|c|}{ FRAP value (mg/ $100 \mathrm{~g} \mathrm{DW})$} & \multicolumn{3}{|c|}{ DPPH value (mg/ $100 \mathrm{~g} \mathrm{DW})$} \\
\hline & Dry (raw) & Soaked (raw) & Cooked & Dry (raw) & Soaked (raw) & Cooked & Dry (raw) & Soaked (raw) & Cooked \\
\hline A & $19.06 \pm 0.49^{\mathrm{Bc}}$ & $17.52 \pm 0.23^{\mathrm{Cc}}$ & $35.95 \pm 0.34^{\mathrm{Ac}}$ & $18.28 \pm 0.16^{\mathrm{Bb}}$ & $17.77 \pm 0.35^{\mathrm{Cb}}$ & $42.77 \pm 0.35^{\mathrm{Aa}}$ & $18.88 \pm 0.17^{\mathrm{Bb}}$ & $17.54 \pm 0.18^{\mathrm{C}}$ & $38.49 \pm 0.72^{\mathrm{A}}$ \\
\hline B & $12.50 \pm 0.27^{\mathrm{Bf}}$ & $11.45 \pm 0.41^{\mathrm{Ce}}$ & $15.69 \pm 0.12^{\mathrm{Af}}$ & $10.22 \pm 0.08^{\mathrm{Be}}$ & $11.05 \pm 0.87^{\mathrm{Be}}$ & $12.01 \pm 0.17^{\mathrm{Ad}}$ & $8.59 \pm 0.13^{\mathrm{B}}$ & $8.45 \pm 0.14^{\mathrm{B}}$ & $9.22 \pm 0.52^{\mathrm{A}}$ \\
\hline $\mathrm{C}$ & $32.08 \pm 0.41^{\mathrm{Bb}}$ & $28.22 \pm 0.98^{\mathrm{Cb}}$ & $52.86 \pm 0.31^{\mathrm{Aa}}$ & $33.88 \pm 0.84^{\mathrm{Ba}}$ & $30.25 \pm 0.79 \mathrm{Ca}$ & $41.32 \pm 1.60^{\mathrm{Aa}}$ & $21.08 \pm 0.39^{\mathrm{Ba}}$ & $17.46 \pm 0.91^{\mathrm{C}}$ & $28.62 \pm 0.89^{\mathrm{A}}$ \\
\hline $\mathrm{D}$ & $14.24 \pm 0.19^{\mathrm{Be}}$ & $12.12 \pm 0.52 \mathrm{Ce}$ & $18.94 \pm 0.36^{\mathrm{Ae}}$ & $5.47 \pm 0.19^{\mathrm{Bf}}$ & $4.21 \pm 0.83^{\mathrm{Cg}}$ & $8.00 \pm 0.14^{\mathrm{Ae}}$ & $3.51 \pm 0.18^{\mathrm{A}}$ & $3.12 \pm 0.32^{\mathrm{A}}$ & $3.07 \pm 0.19^{\mathrm{A}}$ \\
\hline $\mathrm{E}$ & $37.14 \pm 0.29^{\mathrm{Ba}}$ & $35.86 \pm 0.15^{\mathrm{Ca}}$ & $45.78 \pm 0.87^{\mathrm{Ab}}$ & $16.85 \pm 0.59^{\mathrm{Bc}}$ & $14.97 \pm 0.23^{\mathrm{Cc}}$ & $22.54 \pm 0.18^{\mathrm{Ac}}$ & $12.20 \pm 0.18^{\mathrm{Ac}}$ & $11.15 \pm 0.08^{\mathrm{B}}$ & $3.51 \pm 0.09^{\mathrm{C}}$ \\
\hline $\mathrm{F}$ & $13.18 \pm 0.30^{\mathrm{Bf}}$ & $11.84 \pm 1.06^{\mathrm{Be}}$ & $15.98 \pm 0.19^{\mathrm{Af}}$ & $10.69 \pm 0.40^{\mathrm{Be}}$ & $8.26 \pm 0.18^{\mathrm{Cf}}$ & $11.74 \pm 0.29^{\mathrm{Ad}}$ & $7.38 \pm 0.17^{\mathrm{A}}$ & $6.87 \pm 0.11^{\mathrm{B}}$ & $6.76 \pm 1.10^{\mathrm{AB}}$ \\
\hline$G$ & $14.70 \pm 0.13^{\mathrm{Ad}}$ & $10.78 \pm 0.18^{\mathrm{Be}}$ & $10.41 \pm 0.19^{\mathrm{Bg}}$ & $14.87 \pm 0.45^{\mathrm{Ad}}$ & $9.97 \pm 1.05^{\text {Bef }}$ & $8.14 \pm 0.27^{\mathrm{Be}}$ & $11.13 \pm 0.31^{\mathrm{A}}$ & $9.74 \pm 0.25^{\mathrm{B}}$ & $5.38 \pm 0.14^{\mathrm{C}}$ \\
\hline $\mathrm{H}$ & $17.93 \pm 0.24^{\mathrm{Bc}}$ & $14.89 \pm 0.74^{\mathrm{Cd}}$ & $33.82 \pm 0.34 \mathrm{Ad}$ & $15.98 \pm 0.21^{\mathrm{Bc}}$ & $13.45 \pm 0.08^{\mathrm{Cd}}$ & $36.26 \pm 0.58 \mathrm{Ab}$ & $17.01 \pm 0.49^{\mathrm{B}}$ & $15.59 \pm 0.99^{\mathrm{B}}$ & $32.29 \pm 0.66^{\mathrm{A}}$ \\
\hline
\end{tabular}

The criterion for statistical significance was $p<0.05$. 
Table 2. Total phenolic content and antioxidant activity of the boiling water (after protein precipitation)

\begin{tabular}{|c|c|c|c|c|c|c|}
\hline & \multicolumn{3}{|c|}{ Before protein precipitation } & \multicolumn{3}{|c|}{ After protein precipitation } \\
\hline Sample & TPC (mg/100 g DW) & FRAP (mg/100 g DW) & DPPH (mg/100 g DW) & TPC (mg/100 g DW) & FRAP (mg/100 g DW) & DPPH (mg/100 g DW) \\
\hline A & $17.38 \pm 0.06^{\mathrm{Ab}}$ & $16.50 \pm 2.10^{\mathrm{Ab}}$ & $13.45 \pm 0.45^{\mathrm{Ab}}$ & $5.13 \pm 0.11^{\mathrm{Bb}}$ & $5.17 \pm 0.05^{\mathrm{Bb}}$ & $4.28 \pm 0.26^{\mathrm{Ba}}$ \\
\hline $\mathrm{B}$ & $13.04 \pm 0.16^{\mathrm{Ad}}$ & $8.51 \pm 0.14^{\mathrm{Ac}}$ & $5.95 \pm 0.63 \mathrm{Ad}$ & $4.17 \pm 0.08^{\mathrm{Bc}}$ & $3.31 \pm 0.11^{\mathrm{Bd}}$ & $1.76 \pm 0.06^{\mathrm{Bc}}$ \\
\hline $\mathrm{C}$ & $15.12 \pm 0.06^{\mathrm{Ac}}$ & $13.01 \pm 1.58^{\mathrm{Ab}}$ & $4.04 \pm 0.17^{\mathrm{Ae}}$ & $5.58 \pm 0.08^{\mathrm{Ba}}$ & $6.61 \pm 0.05^{\mathrm{Ba}}$ & $1.91 \pm 0.12^{\mathrm{Bc}}$ \\
\hline $\mathrm{D}$ & $4.43 \pm 0.06^{\mathrm{Ag}}$ & $0.87 \pm 0.19^{\mathrm{Ag}}$ & $7.08 \pm 0.63^{\mathrm{Ac}}$ & $2.58 \pm 0.06^{\mathrm{Bf}}$ & $0.85 \pm 0.04 \mathrm{Ag}$ & $0.28 \pm 0.01 \mathrm{Be}$ \\
\hline $\mathrm{E}$ & $10.56 \pm 0.43^{\mathrm{Ae}}$ & $4.97 \pm 0.02^{\mathrm{Ad}}$ & $13.27 \pm 0.53^{\mathrm{Ab}}$ & $5.47 \pm 0.11^{\mathrm{Ba}}$ & $3.18 \pm 0.09^{\mathrm{Bd}}$ & $1.15 \pm 0.67^{\mathrm{Bcd}}$ \\
\hline $\mathrm{F}$ & $5.49 \pm 0.03^{\mathrm{Af}}$ & $2.89 \pm 0.09 \mathrm{Ae}$ & $7.14 \pm 0.29$ Ac & $2.90 \pm 0.13^{\mathrm{Be}}$ & $1.94 \pm 0.02^{\mathrm{Bf}}$ & $0.67 \pm 0.20^{\mathrm{Bd}}$ \\
\hline G & $4.60 \pm 0.24^{\mathrm{Ag}}$ & $2.39 \pm 0.09 \mathrm{Af}$ & $3.88 \pm 0.20^{\mathrm{Ae}}$ & $3.82 \pm 0.13^{\mathrm{Bd}}$ & $2.17 \pm 0.02^{\mathrm{Be}}$ & $0.75 \pm 0.02^{\mathrm{Bd}}$ \\
\hline $\mathrm{H}$ & $28.56 \pm 0.06^{\mathrm{Aa}}$ & $25.59 \pm 0.45^{\mathrm{Aa}}$ & $18.97 \pm 0.12^{\mathrm{Aa}}$ & $4.73 \pm 0.09^{\mathrm{Bc}}$ & $4.12 \pm 0.07^{\mathrm{Bc}}$ & $2.86 \pm 0.06^{\mathrm{Bb}}$ \\
\hline
\end{tabular}

390 Samples A-H are shown in Figure 1. Values represent the mean of three independent experiments \pm S.D. Different capital letters indicate

391 significant differences between measurements made before and after protein precipitation. Different lower case letters indicate differences

392 between samples. The criterion for statistical significance was $p<0.05$. 
Table 3. Bioaccessibility of phenolic compounds from raw and cooked pulses

\begin{tabular}{|c|c|c|c|c|}
\hline \multirow{2}{*}{ Sample } & \multicolumn{2}{|c|}{ Gastric phase } & \multicolumn{2}{c|}{ Intestinal phase } \\
\cline { 2 - 4 } & Raw (mg/100 g DW) & Cooked (mg/100 g DW) & Raw (mg/100 g DW) & Cooked (mg/100 g DW) \\
\hline A & $28.61 \pm 0.88^{\mathrm{Bb}}$ & $43.93 \pm 1.56^{\mathrm{Ab}}$ & $36.44 \pm 1.03^{\mathrm{Ba}}$ & $50.06 \pm 2.54^{\mathrm{Aa}}$ \\
\hline $\mathrm{B}$ & $19.90 \pm 0.25^{\mathrm{Bb}}$ & $35.26 \pm 1.11^{\mathrm{Ab}}$ & $22.22 \pm 0.46^{\mathrm{Ba}}$ & $40.02 \pm 1.08^{\mathrm{Aa}}$ \\
\hline $\mathrm{C}$ & $46.51 \pm 1.28^{\mathrm{Bb}}$ & $55.40 \pm 0.71^{\mathrm{Ab}}$ & $50.16 \pm 0.78^{\mathrm{Ba}}$ & $62.87 \pm 1.36^{\mathrm{Aa}}$ \\
\hline $\mathrm{D}$ & $19.96 \pm 0.80^{\mathrm{Bb}}$ & $39.52 \pm 2.03^{\mathrm{Ab}}$ & $22.47 \pm 0.38^{\mathrm{Ba}}$ & $46.65 \pm 1.40^{\mathrm{Aa}}$ \\
\hline E & $57.29 \pm 1.43^{\mathrm{Bb}}$ & $83.53 \pm 1.67^{\mathrm{Ab}}$ & $65.57 \pm 1.13^{\mathrm{Ba}}$ & $90.27 \pm 1.24^{\mathrm{Aa}}$ \\
\hline F & $20.23 \pm 0.52^{\mathrm{Bb}}$ & $34.02 \pm 2.09^{\mathrm{Ab}}$ & $23.00 \pm 0.39^{\mathrm{Ba}}$ & $40.86 \pm 1.12^{\mathrm{Aa}}$ \\
\hline G & $20.63 \pm 0.70^{\mathrm{Bb}}$ & $28.30 \pm 0.79^{\mathrm{Ab}}$ & $23.25 \pm 0.38^{\mathrm{Ba}}$ & $33.49 \pm 0.93^{\mathrm{Aa}}$ \\
\hline H & $25.35 \pm 0.54^{\mathrm{Bb}}$ & $40.71 \pm 1.46^{\mathrm{Ab}}$ & $30.39 \pm 0.26^{\mathrm{Ba}}$ & $45.38 \pm 0.83^{\mathrm{Aa}}$ \\
\hline
\end{tabular}

Samples A-H are shown in Figure 1. Values represent the mean of three independent experiments \pm S.D. Different capital letters indicate

differences between digestive phases for raw or cooked samples. The criterion for statistical significance was $p<0.05$. 
Table 4. FRAP values of enzymatic digestive extracts from raw and cooked pulses

\begin{tabular}{|c|c|c|c|c|}
\hline \multirow{2}{*}{ Sample } & \multicolumn{2}{|c|}{ Gastric phase } & \multicolumn{2}{c|}{ Intestinal phase } \\
\cline { 2 - 4 } & Raw $(\mathrm{mg} / 100 \mathrm{~g} \mathrm{DW})$ & Cooked $(\mathrm{mg} / 100 \mathrm{~g} \mathrm{DW})$ & Raw $(\mathrm{mg} / 100 \mathrm{~g} \mathrm{DW})$ & Cooked (mg/100 g DW) \\
\hline $\mathrm{A}$ & $21.73 \pm 0.08^{\mathrm{Bb}}$ & $60.09 \pm 1.51^{\mathrm{Aa}}$ & $24.83 \pm 0.99^{\mathrm{Ba}}$ & $64.64 \pm 2.97^{\mathrm{Aa}}$ \\
\hline $\mathrm{B}$ & $12.18 \pm 0.18^{\mathrm{Ba}}$ & $24.86 \pm 0.54^{\mathrm{Aa}}$ & $12.49 \pm 0.15^{\mathrm{Ba}}$ & $25.77 \pm 1.07^{\mathrm{Aa}}$ \\
\hline $\mathrm{C}$ & $42.73 \pm 0.46^{\mathrm{Ba}}$ & $92.17 \pm 4.13^{\mathrm{Aa}}$ & $45.08 \pm 2.26^{\mathrm{Ba}}$ & $96.97 \pm 5.22^{\mathrm{Aa}}$ \\
\hline $\mathrm{D}$ & $7.51 \pm 0.25^{\mathrm{Bb}}$ & $16.24 \pm 0.72^{\mathrm{Ab}}$ & $8.89 \pm 0.32^{\mathrm{Ba}}$ & $20.61 \pm 0.88^{\mathrm{Aa}}$ \\
\hline E & $19.91 \pm 0.18^{\mathrm{Bb}}$ & $34.12 \pm 0.51^{\mathrm{Ab}}$ & $21.11 \pm 0.32^{\mathrm{Ba}}$ & $40.16 \pm 1.35^{\mathrm{Aa}}$ \\
\hline F & $12.41 \pm 0.09^{\mathrm{Bb}}$ & $38.20 \pm 0.80^{\mathrm{Ab}}$ & $14.39 \pm 0.36^{\mathrm{Ba}}$ & $47.40 \pm 3.01^{\mathrm{Aa}}$ \\
\hline G & $17.98 \pm 0.20^{\mathrm{Bb}}$ & $21.85 \pm 2.21^{\mathrm{Ab}}$ & $22.18 \pm 0.24^{\mathrm{Ba}}$ & $28.62 \pm 0.74^{\mathrm{Aa}}$ \\
\hline H & $19.74 \pm 0.21^{\mathrm{Ba}}$ & $39.97 \pm 0.91^{\mathrm{Ab}}$ & $15.15 \pm 0.71^{\mathrm{Bb}}$ & $50.49 \pm 0.64^{\mathrm{Aa}}$ \\
\hline
\end{tabular}

Samples A-H are shown in Figure 1. Values represent the mean of three independent experiments \pm S.D. Different capital letters indicate

differences between digestive phases for raw or cooked samples. The criterion for statistical significance was $p<0.05$. 
Table 5. DPPH values of enzymatic digestive extracts from raw and cooked pulses

\begin{tabular}{|c|c|c|c|c|}
\hline \multirow{2}{*}{ Sample } & \multicolumn{2}{|c|}{ Gastric phase } & \multicolumn{2}{c|}{ Intestinal phase } \\
\cline { 2 - 4 } & Raw (mg/100 g DW) & Cooked (mg/100 g DW) & Raw (mg/100 g DW) & Cooked (mg/100 g DW) \\
\hline A & $20.89 \pm 0.48^{\mathrm{Bb}}$ & $59.03 \pm 0.52^{\mathrm{Ab}}$ & $22.24 \pm 0.48^{\mathrm{Ba}}$ & $69.61 \pm 1.05^{\mathrm{Aa}}$ \\
\hline $\mathrm{B}$ & $10.87 \pm 0.49^{\mathrm{Bb}}$ & $26.89 \pm 0.37^{\mathrm{Ab}}$ & $15.23 \pm 0.56^{\mathrm{Ba}}$ & $30.31 \pm 1.19^{\mathrm{Aa}}$ \\
\hline $\mathrm{C}$ & $24.82 \pm 0.64^{\mathrm{Ba}}$ & $63.95 \pm 1.16^{\mathrm{Ab}}$ & $25.87 \pm 0.31^{\mathrm{Ba}}$ & $71.69 \pm 2.41^{\mathrm{Aa}}$ \\
\hline $\mathrm{D}$ & $5.50 \pm 0.94^{\mathrm{Bb}}$ & $11.76 \pm 0.33^{\mathrm{Ab}}$ & $9.16 \pm 0.93^{\mathrm{Ba}}$ & $24.91 \pm 2.16^{\mathrm{Aa}}$ \\
\hline $\mathrm{E}$ & $15.34 \pm 0.38^{\mathrm{Bb}}$ & $34.21 \pm 0.48^{\mathrm{Ab}}$ & $17.34 \pm 0.52^{\mathrm{Ba}}$ & $38.10 \pm 0.84^{\mathrm{Aa}}$ \\
\hline $\mathrm{F}$ & $10.49 \pm 1.47^{\mathrm{Ba}}$ & $26.26 \pm 0.59^{\mathrm{Ab}}$ & $10.39 \pm 0.75^{\mathrm{Ba}}$ & $32.40 \pm 1.87^{\mathrm{Aa}}$ \\
\hline $\mathrm{G}$ & $14.01 \pm 0.52^{\mathrm{Ba}}$ & $32.76 \pm 0.86^{\mathrm{Ab}}$ & $14.59 \pm 1.09^{\mathrm{Ba}}$ & $37.68 \pm 1.00^{\mathrm{Aa}}$ \\
\hline H & $21.39 \pm 0.75^{\mathrm{Bb}}$ & $51.69 \pm 1.43^{\mathrm{Ab}}$ & $24.50 \pm 0.68^{\mathrm{Ba}}$ & $59.15 \pm 1.95^{\mathrm{Aa}}$ \\
\hline
\end{tabular}

402 Samples A-H are shown in Figure 1. Values represent the mean of three independent experiments \pm S.D. Different capital letters indicate

403 significant differences between raw and cooked samples after the same digestive phase. Different lower case letters indicate significant

404 differences between digestive phases for raw or cooked samples. The criterion for statistical significance was $p<0.05$. 